\title{
AS INTERAÇÕES MOTRIZES DO SAQUE E DA RECEPÇÃO E SUAS INFLUÊNCIAS NO VOLEIBOL: uma compreensão praxiológica
}

\author{
Felipe Menezes Fagundes? \\ Raquel Valente de Oliveira ${ }^{2}$ \\ Bruno Minuzzi Lanes 3 \\ João Francisco Magno Ribas ${ }^{4}$
}

\section{RESUMO}

O Voleibol é um esporte dinâmico devido à velocidade de suas jogadas e à restrição das ações de jogo ao ato de rebater. A partir dessas características, torna-se imprescindível estruturar cientificamente os conhecimentos relacionados aos momentos do Voleibol. Por isso, essa pesquisa discutiu e analisou as interações motrizes estabelecidas nos momentos saque e recepção, ao identificar os elementos oriundos dessas relações. Além disso, propôs-se apresentar outros elementos que não foram contemplados no processo de investigação bibliográfica. Através de uma pesquisa bibliográfica, foram caracterizado os momentos do saque e recepção e suas interações, além de destacar os aspectos relevantes nas diferentes ocasiões que exigem tomadas de decisão. Dessa forma, entende-se que o saque e a recepção precisam ser compreendidos em sua totalidade, e não reduzidos apenas a sua finalidade, o que possibilita um entendimento mais aprofundado da lógica interna do Voleibol.

Palavras-chave: Saque. Recepção. Voleibol. Praxiologia Motriz. Interação Motriz.

1 Graduando em Educação Física. Universidade Federal de Santa Maria (UFSM). Santa Maria/Rio Grande do Sul, Brasil. E-mail: felipemfagundes@live.com

2 Graduanda em Educação Física. Universidade Federal de Santa Maria (UFSM). Santa Maria/Rio Grande do Sul, Brasil. E-mail: raquelvvallente@hotmail.com

3 Mestrando em Educação Física. Universidade Federal de Santa Maria (UFSM). Santa Maria/Rio Grande do Sul, Brasil. E-mail: brunolanes10@hotmail.com

4 Doutor em Educação Física. Professor da Universidade Federal de Santa Maria (UFSM). Santa Maria/Rio Grande do Sul, Brasil. E-mail: ribasjfm@hotmail.com

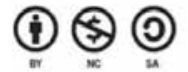




\title{
THE MOTRICES INTERACTIONS OF SERVE AND RECEPTION AND YOURS VOLLEYBALL INFLUENCES: a praxiological understanding
}

\begin{abstract}
Volleyball is a dynamic sport because the speed of their playing and restriction of playing actions the act to hit. From these characteristics, it is essential to structure scientific knowledge related to Volleyball moments. Therefore, this research discussed and analyzed the motrice interactions established in serve and reception moments, to identify elements derived these relationships. In addition, it proposed to introduce other elements, which have not covered by the literature research process. Through a literature research, were characterized the serve and reception moments and their interactions, as well as highlight the relevant aspects in the different occasions that require decision taking. Thus, it is understood that serve and reception needs to be learned in its entirety, and does not reduced only in your purpose, which enables a deeper understanding of Volleyball's internal logic.
\end{abstract}

Keywords: Serve. Reception. Volleyball. Motor Praxiology. Motrice Interaction.

\section{LAS INTERACCIONES MOTRICES DEL SAQUE E DE LA RECEPCIÓN Y SUS INFLUENCIAS EM EL VÓLEIBOL: una compreensión praxiológica}

\section{RESUMEN}

Voleibol es un deporte dinámico en razón de la velocidad de sus jugadas y la restricción de las acciones de juego en el acto de rebatir. A partir de estas características, se hace imprescindible estructurar científicamente los conocimientos relacionados a los momentos del Voleibol. Por lo tanto, esta investigación ha discutido y analizado las interacciones motrices establecidas en los momentos de saque y recepción, identificando los elementos procedentes desas relaciones. Más allá, se propone presentar otros elementos que no fueron considerados en el proceso de investigación bibliográfica. A través de una investigación bibliográfica, ha sido caracterizado por los momentos de saque y recepción y sus interacciones, además de poner en evidencia los aspectos relevantes en las diferentes situaciones que exigen tomadas de decisión. De este modo, se entiende que el saque y la recepción necesitan ser comprendidos en su totalidad y no reducidos apenas a su finalidad, lo que posibilita un entendimiento más profundizado de la lógica interna del Voleibol.

Palabras clave: Saque. Recepción. Voleibol. Praxiología Motriz. Interacción Motriz. 


\section{INTRODUÇÃO}

O Voleibol apresenta-se como um esporte dinâmico e contagiante ao caracterizar-se como um jogo que obrigatoriamente demanda a cooperação, pois sua regra não possibilita a individualização dos ralis ${ }^{5}$, o que proíbe consecutivas intervenções na bola de um único jogador. Além da eminente necessidade de cooperar para se obter êxito no jogo, esse aspecto dinâmico também é dado a partir da restrição quanto ao tipo de habilidade motora que essa modalidade esportiva concede, visto que não se pode alterar o ritmo das disputas de ponto ao conduzir ou reter a bola, pois é válido apenas rebatê-la (BIZZOCCHI, 2008). Com isso, as tomadas de decisão precisam ocorrer no curto espaço de tempo em que a bola realiza sua trajetória no ar. Dessa forma, é necessário que todos indivíduos estejam empenhados em alcançar determinado objetivo, ao cooperar entre si e criar as melhores situações para pontuar e dificultar as ações adversárias.

Ao considerar esses aspectos em relação a facilitar as ações aos companheiros e dificultá-las para os adversários, a Praxiologia Motriz apresenta-se como uma área de conhecimento que objetiva, entre outros aspectos, caracterizar quais interações se manifestam em determinada prática motriz. Dessa forma, o Voleibol configura-se, conforme classifica a Praxiologia Motriz, como uma prática sociomotriz de cooperação-oposição. Entretanto, é trivial o entendimento que o saque, por sua característica, seria um momento em que a cooperação não se evidenciaria de forma tão clara quanto nas demais situações motrizes do jogo, porque não necessita da relação direta com o companheiro, já que sua ação motriz ${ }^{6}$ nada mais é do que colocar a bola em jogo. Ao analisar-se dessa maneira, o saque poderia ser entendido, a partir das relações estabelecidas na lógica de funcionamento do jogo, como um momento no qual só há interações motrizes de oposição. Isso também se aplica à recepção que se caracteriza pela preparação para o ataque e objetiva interceptar a bola advinda do saque, evitando o ponto direto do adversário, ou seja, o ace. Dessa maneira, a recepção apresenta, em suma, interações motrizes de cooperação se percebidos apenas os seus objetivos principais na lógica de funcionamento do jogo.

Para Wise (2005), o saque é comumente conhecido como a primeira linha defensiva, no entanto, a autora afirma que uma boa relação entre um saque eficaz e com baixo nível de erro apresenta-se como uma ferramenta ofensiva vital para o jogo. Ugrinowitsch e Uehara (2001) alertam que esse é o único momento em que o jogador tem total controle das ações, visto que o adversário não consegue influenciar diretamente em sua ação. Já o objetivo da recepção, segundo Shondell (2005), é dirigir a bola até as mãos do levantador, o que possibilita que ele consiga escolher qual atacante acionar, atribuindo a sintonia da equipe a esse momento do jogo. Já Ugrinowitsch e Uehara (2001) apontam que a

5 Rali é uma rotineira expressão utilizada para caracterizar a disputa de cada ponto, ou seja, seu início se dá ao efetuar o saque e finaliza-se a partir do momento em que uma equipe pontue ou cometa alguma infração.

6 É um termo específico da Praxiologia Motriz o qual será mais bem explorado no decorrer desse artigo. Para momentâneo entendimento, ação motriz pode ser compreendida como as ações do jogo, ou seja, os fundamentos básicos de cada prática motriz, o movimento em si. 
recepção é a preparação para o ataque, sendo que sua função não é pontuar diretamente, mas evidenciam que o ponto só ocorrerá a partir de sua boa execução.

Contudo, quando o saque e a recepção estão imersos em sua totalidade na dinâmica do Voleibol, outras relações se estabelecem a partir da finalidade de cada um deles na lógica de funcionamento do jogo. Por mais simples que pareçam, esses dois momentos apresentam uma série de interações e adaptações acerca de suas aplicações, pois além de serem momentos sequenciais no jogo, também se apresentam com objetivos e interações totalmente divergentes. Enquanto o sacador visa colocar a bola no solo da quadra adversária (oposição), o passador busca receber a bola da melhor maneira possível para facilitar o levantamento (cooperação). Esse cenário implica na necessidade de cada jogador antecipar-se e adequar-se à ação motriz do outro, tomando as decisões mais adequadas nas situações impostas pelo jogo, conforme apresenta Ribas (2014) no processo de caracterização dos distintos momentos do Voleibol sob a ótica da Praxiologia Motriz. A partir desses conceitos, se faz necessário aprofundar os desdobramentos das interações motrizes estabelecidas no saque e na recepção e identificar os elementos que surgem dessas relações.

Com isso, objetiva-se caracterizar e sistematizar esses dois momentos do Voleibol, a partir das interações neles estabelecidas, para contribuir com novos conhecimentos no entendimento dessas situações motrizes e, consequentemente, auxiliar no processo de ensino-aprendizagem. Dessa forma, propõe-se uma análise praxiológica do funcionamento do Voleibol, superando conceitos dicotômicos e limitadores do senso comum em relação aos esportes coletivos e como eles normalmente são desenvolvidos em diferentes contextos.

\section{METODOLOGIA}

O ponto de partida desse estudo se constituiu de indagações do Grupo de Estudos Praxiológicos - GEP Brasil em relação à Praxiologia Motriz, ao saque e à recepção. Com isso, foi elaborada uma pesquisa que realizou articulações inicias sobre esses conceitos e suas influências na dinâmica do Voleibol, a qual foi apresentada no $11^{\circ}$ Congreso Argentino y $6^{\circ}$ Latinoamericano de Educación Física y Ciencias, na Universidad Nacional de La Plata, em 2015. Com base nas contribuições atribuídas ao estudo, tornou-se necessário um aprofundamento em relação à temática e amplitude da pesquisa.

Para isso, houve a realização de uma pesquisa bibliográfica que, segundo Gil (2008, p. 50), "é desenvolvida a partir de material já elaborado, constituído principalmente de livros e artigos científicos". Lakatos e Marconi (2003, p. 183) complementam que esse tipo de pesquisa deixa "o pesquisador em contato direto com tudo o que foi escrito, dito ou filmado sobre determinado assunto". Para delimitação do referencial teórico, utilizou-se os quatro critérios apontados por Salvador (1986), os quais são parâmetro temático, parâmetro linguístico, principais fontes e parâmetro cronológico.

Ao dispor-se desses conceitos como base para escolha do referencial teórico, foram consideradas, como temáticas relevantes, obras que discutissem o Voleibol e as relações presentes no saque e/ou na recepção e/ou os elementos derivados dessas interações, bem 
como também abordassem conceitos convergentes aos propostos pela Praxiologia Motriz em relação a essa modalidade. Restringiu-se a pesquisa aos estudos em português devido à facilitação na inferência dos dados, bem como algumas obras em espanhol por serem bases teóricas clássicas em relação ao assunto e às bases epistemológicas adotadas. Nesse sentido, não se fez um recorte temporal para evitar a exclusão de fontes primordiais em relação ao tema da pesquisa, o que justifica a utilização das obras destacadas nessa investigação.

Fundamentado nesse panorama teórico, lançou-se mão da obra "Praxiologia Motriz e Voleibol - Elementos para o Trabalho Pedagógico", organizada por Ribas (2014), como subsídio inicial que caracteriza o Voleibol em seis momentos e sistematiza-os a partir das interações motrizes propostas pela Praxiologia Motriz. O autor sustentou essa análise a partir do Sistema de Classificação CAI, ferramenta criteriosa e científica da Praxiologia Motriz, que visa compreender a lógica interna dos jogos e esportes. Estes critérios de análise também irão orientar o presente estudo nos momentos saque e recepção e serão esclarecidos na sequência.

Ainda foram abordados outros estudos que vieram a corroborar com as ideias apresentadas pela Praxiologia Motriz, como Castro et al. (2014), Frönher (2012), Greco e Benda (2001), entre outros, acerca do saque e da recepção, estudos que apresentam considerações relevantes para a discussão teórica da pesquisa. A utilização desses autores se deu por contemplarem, em suas obras, insumos convergentes aos pressupostos teóricos da Praxiologia Motriz, com o intuito de avançar no que diz respeito ao caráter estritamente biologicista difundido historicamente na Pedagogia dos Esportes.

A partir disso, evidenciaram-se as interações motrizes e seus elementos subjacentes referentes ao saque e à recepção consolidados nas obras que contemplavam a problemática da pesquisa. Em decorrência disso, analisou-se e sistematizou-se esses aspectos em figuras e tabela, ao considerar suas aplicações no contexto do jogo. Posteriormente, propôs-se outros elementos que não foram contemplados pelos autores e que se mostraram relevantes nessa perspectiva de entendimento para o ensino-aprendizagem do Voleibol.

Com isso, ao salientar essas interações motrizes, a Praxiologia Motriz acaba por contemplar a totalidade do problema de pesquisa estabelecido, o que a torna eixo norteador da discussão proposta. No decorrer desse artigo, serão elucidados alguns dos conceitos da Praxiologia Motriz que irão sustentar o estudo.

\section{A Ciência da Ação Motriz}

A Praxiologia Motriz, proposta pelo professor Pierre Parlebas, estuda as ações motrizes de quaisquer situações e práticas motrizes. $\mathrm{O}$ autor a define como "a ciência da ação motriz e especialmente das condições, modos de funcionamento e resultados de seu desenvolvimento" (PARLEBAS, 2001, p. 354). Também conhecida como a Teoria da Ação Motriz, ela tem por objetivo principal "estudar as ações motrizes que emergem em qualquer situação esportiva ou lúdica, como consequência de uma completa trama de relações que se estabelecem entre os participantes [...]" (LAGARDERA; LAVEGA, 2003, 
p. 37). Essa definição proposta por Pierre Parlebas remete à importância do conceito referente à ação motriz.

Para entender-se de fato a relevância das ações motrizes na proposta de análise da Praxiologia Motriz, faz-se necessário compreender os aspectos epistemológicos os quais essa teoria se pauta. Fundamentada em uma perspectiva Estruturalista (HERNÁNDEZ MORENO; RODRÍGUEZ RIBAS, 2004 e RIBAS, 2014), a Praxiologia Motriz entende as práticas motrizes como sistemas praxiológicos. Isso significa que ao assumir as características de um sistema, é necessário compreender que a realidade se faz de modo complexo e interativo e só adquire sentido quando compreendido em sua totalidade (LAVEGA; LAGARDERA, 2001).

Com isso, todo o sistema praxiológico está submetido a uma convenção regulamentária, a qual corrobora a forma como o jogo se estrutura, ao passo que esse acordo pode ser institucionalizado ou tratado entre os jogadores. Dessa forma, regulamenta-se como o funcionamento do jogo ocorrerá, no que diz respeito às regras descritivas (que delimitam o espaço, tempo, sujeitos e suas competências), às normas (tratam da conduta e comportamento dos jogadores) e às regras de jogo, as quais explicitam os requisitos necessários para realizar as ações motrizes de determinado sistema praxiológico (LAVEGA; LAGARDERA, 2001).

Visto que as regras estabelecem as possíveis interações do jogador no sistema praxiológico, evidenciam-se as possíveis ações motrizes de cada prática motriz. Lagardera e Lavega (2001) afirmam que as ações motrizes derivam de cada sistema praxiológico e emergem da relação direta da lógica interna. Assim, a ação motriz acaba configurando-se como o movimento em si, no entanto, não por ele mesmo, visto que ela assume diversas características e influências em relação ao sistema o qual está inserida e ao sujeito que a provêm, resultando em diferentes condutas motrizes ${ }^{7}$.

Para apresentar uma das ferramentas de compreensão das práticas motrizes, Parlebas (1987) elaborou o chamado Sistema de Classificação CAI, que tem por finalidade classificar jogos e esportes a partir de suas lógicas internas. Para a elaboração desse sistema, ele levou em consideração a presença/ausência de companheiros (C) e/ou adversários (A) e a relação com o entorno físico, ou seja, a presença/ausência da incerteza do meio (I). Ao que diz respeito a (in)existência de interação motriz entre os jogadores que atuam no jogo, Parlebas (1987) elucida que há quatro grandes grupos que são: sem interação ou psicomotriz; interação de oposição ou sociomotriz de oposição; interação de cooperação ou sociomotriz de cooperação e interação de oposição e cooperação simultânea ou sociomotriz de cooperação-oposição.

Lagardera e Lavega (2003, p. 79) afirmam que, nos esportes coletivos de modo geral, "os jogadores intervêm com a colaboração de companheiros e a oposição de adversários. Ao se tratar das práticas correspondentes aos esportes de duelo coletivo". Nessas

7 Para Parlebas (2001), quando uma ação motriz é realizada por determinado sujeito, essa ação torna-se uma conduta motriz, visto que as características de quem a produz mostram-se evidentes. Mesmo que determinado sistema praxiológico condicione a forma como os indivíduos podem atuar no jogo, cada um deles apresentará uma forma única de realizar essas ações motrizes, apresentando condutas motrizes ricas em identidade e em significado para quem joga. 
referidas práticas, os jogadores devem ler e interpretar o comportamento motor dos outros participantes. Ao mesmo tempo em que as mensagens devem ser as mais claras possíveis aos seus companheiros, as mesmas devem ser obscuras e duvidosas para seus adversários, o que torna incerta as atitudes que irão desempenhar no decorrer do jogo (RIBAS, 2014).

O entendimento que a Praxiologia Motriz traz com o conceito de lógica interna e suas respectivas ações motrizes são de suma importância para a atuação dos jogadores nos diferentes momentos do Voleibol. Conforme Lagardera e Lavega (2003, p. 67) a lógica interna, por sua vez, é "o modo peculiar como são pré-determinadas as ações motrizes de todo o jogo esportivo". A mercê desse entendimento referente à lógica interna, fornecido pela Praxiologia Motriz, é possível que se compreenda como são estabelecidas as relações de cooperação e oposição no Voleibol. A partir disso, a Praxiologia Motriz entende que as interações motrizes ${ }^{8}$ podem ser estabelecidas pelos jogadores das seguintes maneiras: entre os demais participantes, com o material/elemento, com o espaço e/ou com o tempo do jogo.

É valido elucidar que a Praxiologia Motriz não se apresenta como uma abordagem de ensino da Educação Física. Este criterioso conhecimento permite analisar as práticas motrizes, dando um embasamento aos professores e profissionais dessa área em relação à lógica interna das práticas motrizes e das possíveis ações motrizes que derivam desse contexto. No entanto, a aplicabilidade da Praxiologia Motriz, em paralelo a uma concepção de ensino bem alicerçada, mostra-se como conhecimentos estritamente necessários para que se possibilite desenvolver toda a potencialidade e pluralidade que determinada prática motriz apresenta. Em vista das características do Voleibol de quadra, prender-se-á as relações existentes entre jogadores, que quando estabelecidas entre os companheiros denomina-se comunicação e quando evidenciada com os adversários, chama-se contracomunicação. Dessa forma, a partir dessas interações propostas por Parlebas, é possível realizar a divisão do jogo de Voleibol, como propõe Ribas (2014), em seis momentos distintos: saque, recepção, levantamento, ataque, bloqueio e defesa.

Ao compreender-se o Voleibol composto por diferentes momentos, se faz evidente o entendimento de que esses se relacionam e que, em suma, a tomada de decisão efetuada em cada momento do jogo se faz em decorrência da ação motriz ou de sua análise realizada previamente a sua execução. Com esse pressuposto, propõe-se que os processos de ensino-aprendizagem dos esportes de cooperação-oposição também se preocupem com as interações que se fazem presentes na lógica interna. Fotía (2013, p. 76) afirma que o aluno, na iniciação, "precisa desenvolver uma compreensão de sua lógica interna através de tarefas globais (jogos simplificados e modificados), em vez de utilizar-se de técnicas analíticas". Dessa maneira, a partir das relações estabelecidas, é possível desenvolver as referidas ações motrizes aplicadas em contextos específicos do Voleibol, ou seja, em seus diferentes momentos de jogo.

8 Segundo Parlebas (2001), a interação motriz se dá quando, no momento em que determinado participante realiza uma tarefa motriz, seu comportamento motor influencia visivelmente nas ações motrizes de um ou de vários dos participantes do jogo. 
Na sequência, serão abordadas as interações propostas e caracterizadas por Ribas (2014), bem como os elementos delas provenientes e apontar suas eminências relativas ao saque e à recepção. A partir disso, discutir-se-á as aplicações dessas relações no contexto do jogo e o modo como elas acontecem, na configuração dessas relações no que diz respeito à comunicação práxica, ao momento de execução de leitura e às possibilidades de interpretação que podem ser realizadas no saque e na recepção no Voleibol. Vale ressaltar que as interações abordadas incluem aspectos básicos, que são possíveis de serem desenvolvidos em quaisquer níveis de ensino, porém também contempla relações mais complexas, que se enquadram na perspectiva do alto rendimento. Cabe ao leitor perceber quais delas se aplicam mais ao contexto que serão desenvolvidos esses dois momentos do Voleibol.

\section{REFERENCIAL TEÓRICO}

\section{Saque: Além de "Colocar a Bola em Jogo"}

O saque é o primeiro momento do Voleibol, no qual a bola é posta em jogo, para dar início ao rali. Esse momento tem por objetivo principal dificultar a recepção da equipe adversária, para que a mesma não consiga realizar adequadamente a preparação para o ataque. Assim, o saque é "uma arma de ataque muito eficaz, um fundamento importante para se conseguir um ponto direto ou aquele que proporciona um controle maior da ação seguinte" (CASTRO et al., 2014, p. 37).

Em linhas gerais, o saque é um momento que gera influências diretas na ação organizacional do sistema ofensivo da equipe adversária, (assimm) tornando-se uma importante ferramenta para obtenção de vantagem no início da disputa de cada ponto. Ribas e Araújo (2014) destacam que independentemente da forma como o saque se expresse, quem o executa precisa realizar leituras e análises concisas da situação de jogo para elencar os elementos que são relevantes para decidir como, onde e em qual adversário sacar. Com isso, sistematizou-se esse momento do jogo em uma figura, evidenciando as interações que o saque propicia em relação aos demais momentos do jogo, bem como os elementos oriundos de cada interação motriz estabelecida. Essa figura é fruto de uma adaptação dos elementos propostos por Ribas e Araújo (2014) a partir das interações do saque com os demais momentos.

Essa figura possibilita perceber que o saque apresenta veementes interações de oposição com a recepção e com o levantamento adversário, dessa forma, surgem diversos elementos que se mostram relevantes durante a realização do saque. Além disso, é necessário perceber que podem ocorrer situações que não são eventualmente previstas no contexto do jogo, potencialmente capazes de influir na ação motriz do sacador. Por fim, ainda se propõe um elemento que pode surgir de um contexto comunicativo ${ }^{9}$, ou seja,

9 Esse elemento não surge de uma interação motriz de cooperação propriamente dita, mas sim de uma possibilidade estratégica em relação ao esquema tático do sistema defensivo de cada equipe. Essa possibilidade comunicativa será mais bem elucidada no decorrer desse artigo. 
proveniente de uma estratégia defensiva que supera a necessidade eminente de pontuar através do saque, mas sim possibilitar a retomada da posse de bola e o contra-ataque a partir de uma relação bem-sucedida entre o saque, o bloqueio e a defesa.

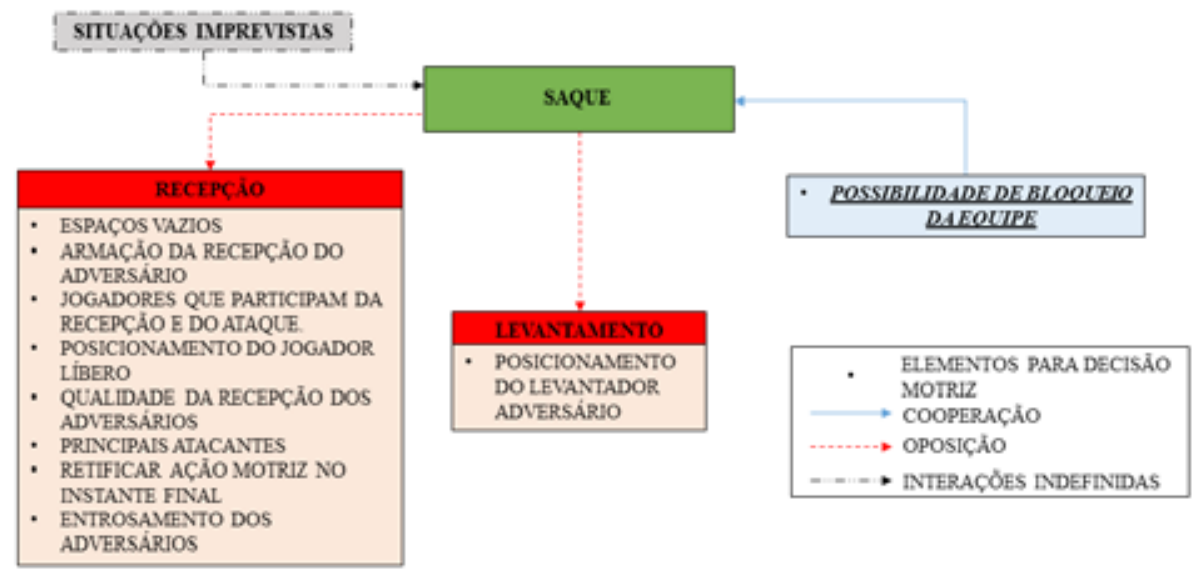

Figura 1 - Interações Motrizes Diretas e os Elementos para Decisão Motriz do Saque em relação aos Momentos do Voleibol Fonte: Elaborada pelos autores.

\section{Recepção: Uma Estratégia Além do Passe}

A recepção é um momento no qual a equipe se prepara para organizar o ataque que possibilita a sequência da disputa do ponto e, consequentemente, do jogo, pois se configura em interceptar o saque adversário e evitar que a bola toque o solo. Assim, é por meio dessa ação que a organização ofensiva da equipe é formada, caracterizando-se como uma ação chave para a continuidade do jogo (FRÖNHER, 2012). Entendido na perspectiva praxiológica, esse momento constitui-se de relações de cooperação e oposição simultâneas, ao opor-se com o saque, tentando interceptá-lo, e ao mesmo tempo, cooperando com o levantador, de forma a realizar o passe adequadamente para facilitar a sua ação posterior.

Com isso, podemos concluir que a recepção age de maneira contracomunicativa com o saque e, em sequência, estabelece uma ação comunicativa com o levantamento. Ribas et al. (2014, p. 71) corrobora com isso ao afirmar que "durante a recepção, as ações de cooperação deverão ser altamente organizadas para evitar que o adversário atinja seu objetivo. Por isso, elementos de comunicação serão essenciais para esta ação". Dessa forma, esse sistema de comunicação se dá, além dos fatores já mencionados acima, através das funções de cada jogador em quadra e suas respectivas áreas de atuação. Ao considerar-se o sistema de comunicação e contracomunicação estabelecidos na recepção, bem como elucida o autor, apresenta-se a seguir uma figura que representa as interações motrizes 
da recepção em relação aos demais momentos do Voleibol e seus respectivos elementos. Essa figura é fruto de uma adaptação dos elementos propostos por Ribas et al. (2014) no momento da recepção, aliados as interações estabelecidas entre os momentos do jogo.

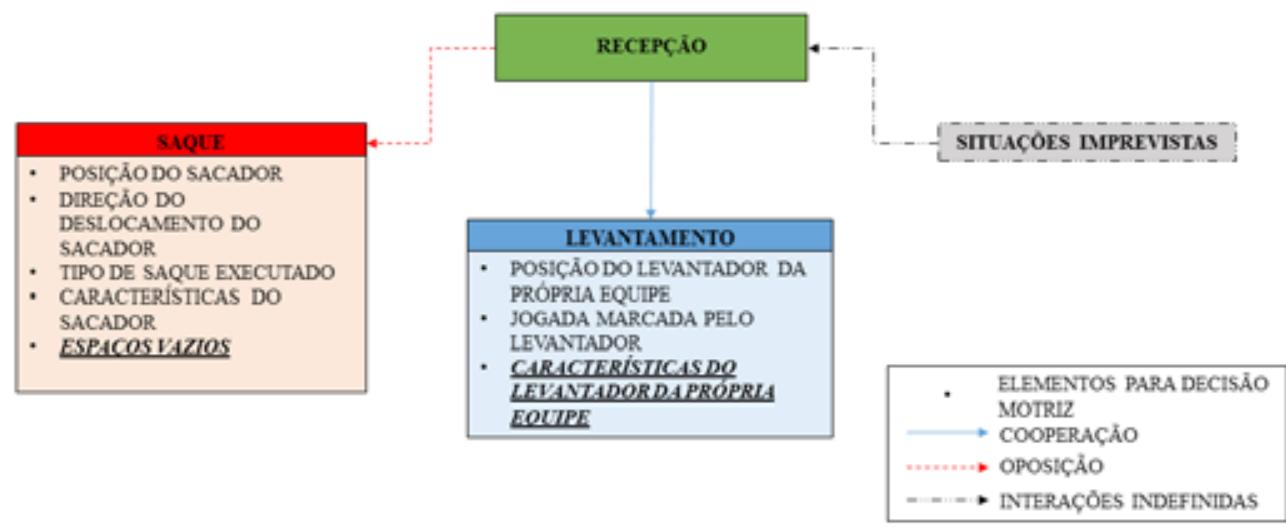

Figura 2 - Interações Motrizes Diretas e os Elementos para Decisão Motriz da Recepção em relação aos Momentos do Voleibol Fonte: Elaborada pelos autores.

A partir da figura apresentada, é possível verificar a interação motriz de comunicação entre a recepção e o levantamento e a de contracomunicação entre o saque e a recepção. Além disso, é possível evidenciar os elementos relevantes para tomada de decisão da recepção. Ao analisar a sistematização proposta por Ribas (2014), sugere-se a reconsideração de dois elementos quanto ao momento da análise, sendo um referente ao saque e outro à recepção, na qual serão explicados no decorrer do texto. Ainda, apresentam-se as situações imprevistas derivadas do contexto do jogo que podem emergir de maneira relevante para a tomada de decisão.

\section{RESULTADOS E DISCUSSÃO}

\section{Novos Entendimentos para Saque e Recepção}

Ao tratar-se como pressuposto as interações propostas por Ribas (2014), consegue-se ver que tanto o saque quanto à recepção são momentos extremamente complexos e que dependem de vários aspectos ligados diretamente a sua lógica interna e as relações estabelecidas entre companheiros e adversários. Assim, identifica-se que é necessário ter um entendimento global dos momentos do Voleibol, em suma, da recepção e do saque, o que indefere em suas caracterizações apenas como ofensivo ou defensivo, pois cada situação motriz não está isolada no sistema praxiológico. 
Não se pode reduzir a recepção a um momento exclusivamente defensivo, pois a sua realização eficaz é essencial para a construção do sistema de ataque, o que a torna também uma ferramenta ofensiva. O mesmo ocorre com o saque, pois mesmo ao opor-se com a outra equipe, quando bem executado, pode desestabilizar o ataque adversário, facilitando o sistema de bloqueio e de defesa, por isso também se configura em uma ferramenta defensiva. Com isso, não se propõe aqui uma nova classificação ou denominação para o saque e para a recepção, mas sim um entendimento amplo sobre as consequências que esses momentos têm no jogo, indo além da sua aplicação instantânea, ao entender que os momentos do Voleibol são lineares e, consequentemente, uma situação motriz influencia na outra. Ao repensar-se esses dois momentos do jogo, com esse enfoque praxiológico consegue-se perceber outros elementos que também se estabelecem de forma relevante para a tomada de decisão durante o saque e a recepção, os quais serão explicados em destaque nas suas aplicações na lógica interna.

Embasado no Modelo Pendular de Tomada de Decisão de Greco (2006), Ribas (2014) aponta que esses elementos podem ser analisados pelos jogadores de três formas: análise antecipada, análise situacional e conhecimento prévio do adversário. A análise antecipada constitui-se do diagnóstico realizado pouco antes da execução da ação motriz dos jogadores e constituiu-se a primeira condição de análise acerca da equipe adversária ou de sua equipe. A análise situacional refere-se à leitura feita durante a execução da ação motriz dos participantes, ou seja, é a última leitura a ser realizada antes da execução das ações dos adversários e dos companheiros. Por sua vez, o conhecimento prévio do adversário refere-se ao conhecimento das características da outra equipe ou de algum jogador específico e de suas ações motrizes, no qual auxiliará no processo de leitura do jogo, obtida por meio de vídeos e observações. Com base nos resultados encontrados no processo da pesquisa bibliográfica, percebeu-se a carência de alguns elementos que se evidenciam relevantemente no contexto do Voleibol. A seguir, serão apresentadas as proposições derivadas da necessidade apontada pela pesquisa.

No momento em que o jogador executa o saque, percebe-se que a Possibilidade de Bloqueio da Sua Equipe é um elemento relevante para tomada de decisão que influencia na ação motriz do sacador, pois ao perceber que seus companheiros com boa capacidade de bloqueio estão na rede, o jogador pode optar por um saque mais cauteloso. Nesse caso, se objetiva minimizar o risco de erro ao sacar, passando a bola para o lado adversário, e tentar pontuar com o sistema de bloqueio. Esse elemento evidencia-se mais em alto nível, pois é uma tática normalmente aplicada quando a equipe busca abrir vantagem no placar. Assim, o treinador também pode realizar a substituição de alguns jogadores com boa capacidade de bloqueio, na possibilidade de intimidar o ataque adversário. Castro et al (2014) afirmam que ao sacar em zonas determinadas, dificulta-se a construção do ataque por parte da equipe adversária e facilita as ações de bloqueio e defesa. Assim, entende-se que a possibilidade de bloqueio da sua equipe se torna um elemento relevante porque há uma mudança direta na ação motriz do sacador ao estabelecer esse tipo de relação de comunicação com o bloqueio. 
Já sobre a recepção, nota-se que há uma contundente relação com o levantador, pois a mesma se configura taticamente para deixá-lo livre do passe, na busca por facilitar suas ações. Dessa forma, também se tornam relevantes as Características do Levantador da Própria Equipe como elemento de tomada de decisão. Por exemplo, se o levantador não apresentar estatura privilegiada, a recepção deve ser realizada mais distante da rede, para que seja possível a execução do levantamento. Outra característica importante a ser considerada é a capacidade de deslocamento do levantador, o que faz com que o passe precise ter uma parábola maior caso ele não tenha uma capacidade de deslocamento adequada, ainda mais em sistemas de jogo que utilizam infiltração. Matias (2009, p. 137) corrobora com isso ao afirmar que "quando a qualidade do primeiro toque é baixa, as opções dos levantadores limitam-se basicamente a uma ação de correção". Também se acredita que essa interação se faz relevante, pois serão realizadas alterações na forma de execução da recepção devido as mais diversas características apresentadas pelo levantador da equipe.

Outro elemento que foi evidenciado para a recepção foi relativo aos Espaços Vazios, sendo que essa relação já foi citada por Ribas (2014) na discussão referente ao saque, mas não abordada como uma possibilidade de elemento relevante para tomada de decisão na recepção. Em nível de contracomunicação, a estruturação da recepção pode deixar propositalmente um espaço vazio na quadra, para induzir o saque naquela região, e, dessa forma, possibilitar a antecipação e a realização bem-sucedida do passe. Esse elemento se torna pertinente a partir do momento em que há uma alteração da armação da recepção e uma emissão de uma mensagem que induz determinada leitura por parte do adversário, com o intuito de surpreendê-lo.

Por fim, ainda se propõe que o elemento referente à Posição do Levantador da Própria Equipe possa ser considerado tanto antecipadamente a ação motriz, como evidenciada por Ribas (2014), quanto durante a execução da recepção, ou seja, em uma Análise Situacional. Como o levantador precisa se deslocar para realizar o levantamento, é relevante perceber no momento da realização do passe: a distância entre o passador e o levantador, o local na quadra que ele se encontra e, caso ocorra, a trajetória de infiltração do mesmo. A Análise Situacional referente a esse elemento mostra-se crucial para a eficácia do momento da recepção.

A partir disso, sistematizou-se os elementos propostos por Ribas (2014) em tabela para que melhor possam ser percebidas essas relações, sendo estruturada a partir do tipo de interação motriz (comunicação ou contracomunicação) e sobre o momento de realização da leitura do jogo. Os elementos grifados na tabela abaixo foram propostos com base na leitura, interpretação, análise e discussão do referencial teórico abordado. Com isso, novas considerações podem ser feitas em relação a esses elementos, com o intuito de melhorá-los qualitativamente. 
Tabela 1 - Elementos Oriundos das Interações entre Saque e Recepção.

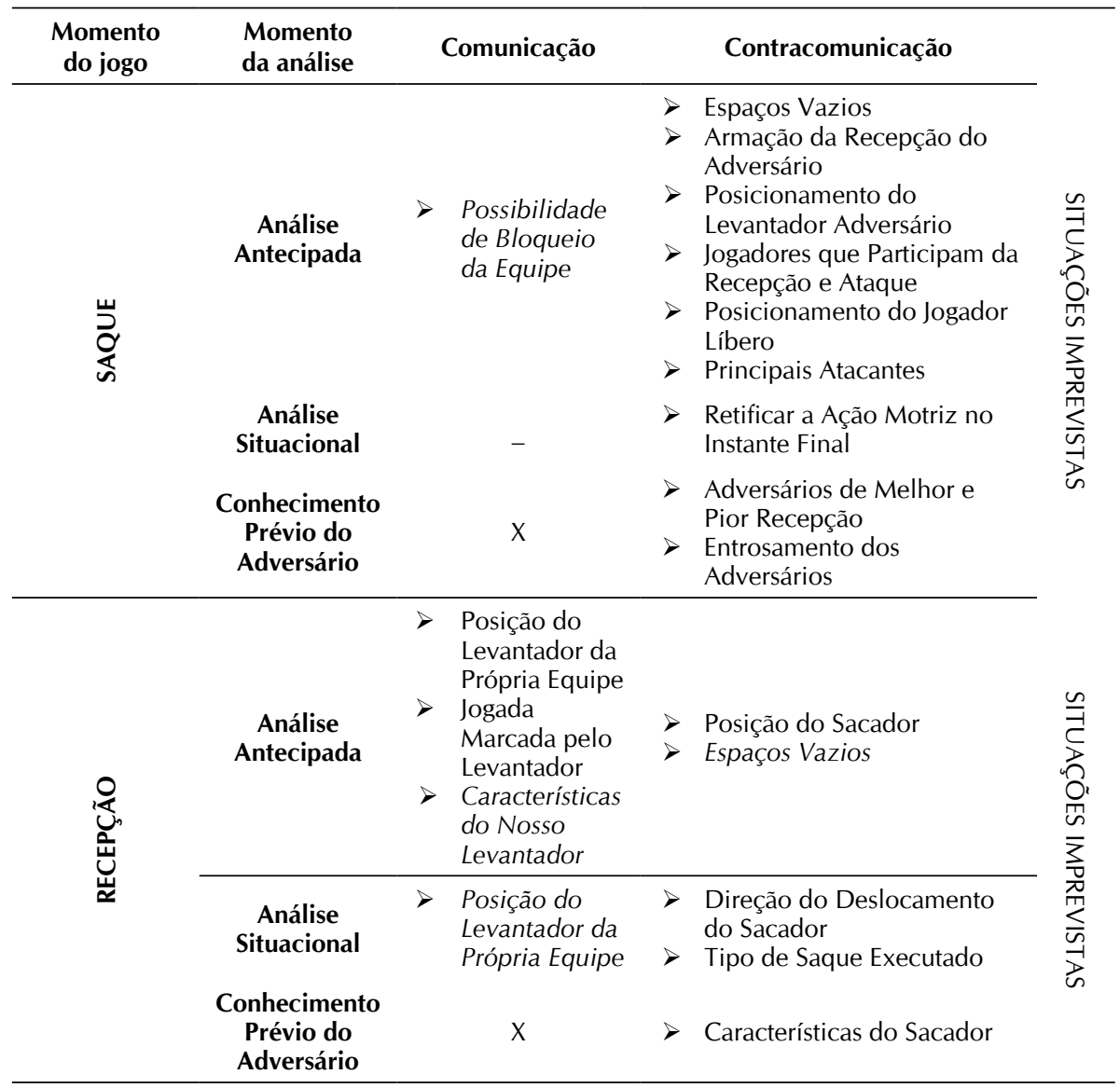

Fonte: Elaborada pelos autores.

A partir da tabela apresentada, pode-se constatar que as interações de comunicação e contracomunicação evidenciadas em decorrência da realização da leitura do jogo, além de seus respectivos elementos dependem, diretamente, do caráter que o jogo assume. No contexto esportivo do Voleibol, o caráter do jogo é uma variável que diz respeito a sua influência sobre a conduta motriz de seus jogadores. O mesmo é um dos elementos da lógica externa ${ }^{10}$ e influencia diretamente nas ações motrizes dos participantes e em suas condutas motrizes, ou seja, no modo como cada jogador realiza essas ações durante o jogo.

10 Segundo Parlebas (1999, p. 220) a lógica externa é o “modo particular com que pode ser objeto de interpretação externa a lógica de todo jogo esportivo". Ainda pode-se acrescentar que ela pode assumir diferentes sentidos culturais, pois está associada a compreensão do contexto sociocultural em que o sistema praxiológico está inserido. 
Com isso, o esporte pode manifestar-se de diferentes maneiras, com objetivos e finalidades distintas em nossa sociedade, dentre eles pode-se citar o esporte manifestado pelo lazer, na prevenção da saúde, no meio escolar, na recuperação e reabilitação e no esporte de alto nível (GRECO; BENDA, 2001). Assim, pode-se proferir que o caráter que o jogo assume acarretará influência no enfoque que as interações estabelecidas entre os momentos do jogo e em seus elementos irão assumir, tanto de cooperação quanto de oposição. Corroborando com isso, Tubino (1992) propõe os conceitos de Esporte-performance, Esporte-participação e Esporte-educação, nos quais suas interações e seus elementos se fazem diferentes perante o caráter do jogo.

Ao considerar esses conceitos, o esporte manifestado nas aulas de Educação Física escolar poderá desenvolver determinados valores, comportamentos, relacionamentos e inclusão de alunos, sua criticidade, além da aprendizagem de seus específicos conteúdos. Dessa maneira, ao apresentar-se com um caráter educacional, as interações de oposição provavelmente não serão tão evidentes, pois objetiva-se a sequência e a continuidade dos momentos, visto que a competição não é sua principal finalidade. Por isso, os elementos que se fazem presentes na oposição não serão altamente constatados quando comparados aos da cooperação, pois para que ocorra maior sequência dos momentos do jogo, esses elementos de comunicação devem ser mais abordados no processo de ensino-aprendizagem.

Por sua vez, o esporte com caráter participativo, praticado como forma de lazer, se apresenta semelhantemente ao anterior. Seu objetivo é a diversão e a sensação de bem-estar, por isso que as interações de contracomunicação, juntamente com seus elementos, fazem-se pouco presente. Nesse caso, assim como no esporte com caráter educacional, tornam-se mais evidentes as interações de comunicação e seus respectivos elementos, não só entre os jogadores da mesma equipe, mas inclusive entre adversários. Por exemplo, para que o jogo tenha sua essência esperada, necessita-se que ambas as equipes demonstrem certo equilíbrio, pois é mais atrativo que a bola permaneça mais tempo em jogo, para possibilitar maior tempo de disputa dos pontos.

Já no esporte-performance, no qual almeja-se a participação em competições formais e a busca incessante pela vitória, as interações, tanto de comunicação quanto de contracomunicação, são claramente evidenciadas, pois os jogadores não medem esforços para obter melhores resultados. Pode-se, com isso, trazer um exemplo acerca do saque e da recepção, no qual, nessas condições, o saque buscará, com maior empenho, dificultar ou anular a recepção da equipe adversária, com predominância da contracomunicação, quando comparado ao caráter educacional e/ou participativo. Assim sendo, os elementos de cooperação e oposição também se fazem presentes à medida que se realizam leituras e análises do jogo e das ações motrizes a todo o momento, tanto de companheiros quanto de adversários.

\section{CONCLUSÃO}

Objetivou-se, nesse estudo, caracterizar o saque e a recepção como momentos relevantes para a sequência do jogo de Voleibol, pois se ambos não forem compreendidos 
e executados de forma satisfatória, os demais momentos poderão ser comprometidos. Essa importância do entendimento global dos seis momentos do jogo faz-se necessária para que se tenha uma concepção mais crítica e teórica do fenômeno esportivo como um todo. É preciso também entender cada um dos momentos, seus principais objetivos, assim como suas características relevantes, suas interações de cooperação e oposição, juntamente com seus elementos. Além disso, realizar leituras e interpretações das ações motrizes dos jogadores tornam-se eminentemente relevantes para atuar de forma autônoma e consciente no sistema de jogo.

Para isso, é necessário e de extrema relevância que o professor tenha um conhecimento aprofundado em relação à modalidade que se busca desenvolver. Como já citado anteriormente, essa pesquisa não é voltada apenas para o contexto escolar, podendo também ser destinado ao alto nível e demais situações de ensino-aprendizagem. Dessa forma, o profissional que irá trabalhar com o Voleibol, independentemente do caráter do jogo, precisará ter o conhecimento suficiente acerca das interações e elementos de cooperação e oposição dos momentos do jogo. Ainda, precisam estar presentes no processo de ensino-aprendizagem as estruturas de atividades que contemplem as leituras das ações motrizes de companheiros e adversários, bem como suas tomadas de decisão, para que se instigue os alunos sobre esses elementos.

Ademais, o professor deve saber justificar a importância desse conhecimento sobre o funcionamento interno dos jogos, incluindo em sua metodologia de ensino esses elementos, ao enfatizar as interações estabelecidas entre os momentos do jogo. Na inclusão desses novos conhecimentos em suas aulas, o professor/profissional estará auxiliando seus alunos a adquirirem o devido entendimento acerca da lógica interna do Voleibol (FOTÍA, 2013).

Ao aplicar esses elementos no processo de ensino-aprendizagem, o professor possibilitará o melhor entendimento das relações estabelecidas entre sua equipe, os elementos que devem ser observados durante o jogo e as análises referentes aos companheiros, desde o espaço da quadra até as características individuais. O mesmo acontece nas relações com os adversários, pois quando o jogador passa a visualizar e interpretar as ações de seus oponentes, terá melhores condições de analisar adequadamente o sistema de jogo e obter resultados satisfatórios em suas ações e na sua aprendizagem em relação ao funcionamento do jogo. Isso se torna possível pela realização das leituras adequadas, compreensão de suas características, as possibilidades de execuções, o entrosamento da equipe, os espaços, o posicionamento em quadra, dentre outros elementos.

Sendo assim, quando o jogador apropria-se da lógica interna do esporte no qual está inserido, consegue executar as ações motrizes durante o jogo com convicção da sua tomada de decisão, não apenas a reproduzindo, mas compreendendo seu significado. No entanto, essa reprodução de movimento, muitas vezes é associada ao ensino da técnica, veementemente criticada quando inserida no meio escolar, visto que é confundido com o ensino tecnicista. Porém, a técnica tem relevância no desenvolvimento do sistema de jogo, pois as ações motrizes que constituem determinado esporte são compostas pelo processo indissociável entre técnica e tática de qualquer ação motriz. Isso gera um sentido que ultrapassa e supera a simples reprodução e repetição dos movimentos já padronizados. 
Para corroborar com essa ideia, Bracht (2009) afirma que é um grande equívoco quando se associa a técnica ao ensino tecnicista, pois ela está presente em qualquer prática e, portanto, não se deve aboli-la, mas sim dotá-la de novos sentidos e finalidades pedagogicamente construídas.

Dessa forma, quando o profissional vai além do ensino da técnica e abrange também o conhecimento acerca da lógica interna, estará desenvolvendo e ampliando a autonomia do aluno a partir da análise crítica do contexto do jogo, pois dessa maneira ele entenderá a importância da realização das leituras e análises do contexto esportivo. Assim, instiga-se a formação de um aluno crítico e autônomo desde o objeto de estudo da Educação Física até suas interlocuções com a sociedade. Kunz (2004) afirma que a intenção do esporte pedagógico não pode ser apenas de assessorar o aluno para melhor praticar o esporte com autonomia, mas sim de torná-lo reflexivo mediante os tipos de manifestações esportivas existentes em seu meio. Com isso, ao entender o jogo de maneira criteriosa, possibilita-se que aluno desenvolva sua criticidade perante a sociedade na qual ele está inserido. Assim, o aluno passa a ampliar o entendimento do esporte e sua realidade e abordar, de maneira autônoma e independente, as diferentes relações sociais e as demais situações impostas pelo dia a dia. Com isso, o jogo contribui, a partir de sua problematização, para que se conheça mais sobre si mesmo e seu papel na sociedade.

Com essa pesquisa, foi possível abranger, detalhadamente, as interações motrizes e os elementos presentes no saque e na recepção. Além disso, constatou-se a eminência do conhecimento científico em relação às interações motrizes e aos elementos de cooperação e oposição nesses dois momentos do Voleibol. Os novos conhecimentos apontados no estudo poderão auxiliar professores e outros profissionais da área a desenvolver um trabalho mais didático e pedagógico, ajudando-os no processo de ensino-aprendizagem desses dois momentos elementares do Voleibol.

\section{REFERÊNCIAS}

BIZZOCCHI, C. O voleibol de alto rendimento: da iniciação à competição. Barueri: Manole, 2008.

BRACHT, V. Esporte de rendimento na escola. In: STIGGER, M. P.; LOVISOLO, H. (Orgs.). Esporte de rendimento e esporte na escola. Campinas, SP: Autores Associados, 2009. p. 11-26.

CASTRO, H. O; CAVALLI, I; SILVA, C. J. A.; GRECO, P. J. Interação no Curso das Ações de Saque e Bloqueio no Voleibol Juvenil. Campinas - Conexões: revista da Faculdade de Educação Física da UNICAMP, v. 12, n. 3, p. 34-54, 2014.

FOTÍA, J. Voleibol, Lógica Interna e Iniciación. Las Palmas Del Gran Canaria: ACCAFIDE, Acción Motriz, v. 10, 2013. Disponível em: < http://www.accionmotriz.com/ documentos/revistas/articulos/10_6.pdf > Acesso em: 12 jan. 2015.

FRÖNHER, B. Vóleibol, juegos para el entrenamiento. $-2^{\mathrm{a}}$ ed. $2^{\mathrm{a}}$ reimp. Buenos Aires: Stadium, 2012 
GIL, A. C. Métodos e Técnicas de Pesquisa Social. São Paulo, Editora Atlas S.A., 6 a edição, 2008.

GRECO, P. J. Conhecimento tático-técnico: modelo pendular do comportamento e da ação nos esportes coletivos. Revista Brasileira de Psicologia do Esporte e do Exercício, v. 0, p. 107-129, 2006.

GRECO, P. J.; BENDA, R. N. Iniciação esportiva universal. Belo Horizonte: Editora da UFMG, 2001.

HERNÁNDEZ MORENO, J.; RODRÍGUEZ RIBAS, J. P. La Praxiologia Motriz: fundamentos y aplicaciones. Barcelona - Espanha, INDE publicaciones, 1ª edición, 2004.

KUNZ, E. Transformação didático-pedagógica do esporte. ljuí: UNIJUÍ, 6 a edição, 2004. LAGARDERA OTERO, F.; LAVEGA BURGUÉS, P. Introducción a la praxiología motriz. Barcelona: Editorial Paidotribo, 2003.

LAGARDERA OTERO, F.; LÓPEZ VILLAR, C.; GONZÁLEZ ALONSO, O. As condutas motrizes introjetivas. In: RIBAS, J. F. M. (Org.). Jogos e esportes: fundamentos e reflexões da praxiologia motriz. Santa Maria: Editora da UFSM, 2008. p. 189-207

LAKATOS, E. M; MARCONI, M. A. Fundamentos de Metodologia Científica - São Paulo: Editora Atlas, $5^{\mathrm{a}}$ edição, 2003.

MATIAS, C. J. A. DA S. O Conhecimento Tático Declarativo e a Distribuição de Jogo do Levantador de Voleibol: da Formação ao Alto Nível. Dissertação de Mestrado, Universidade Federal de Minas Gerais, 2009.

PARLEBAS, P. Juegos, deporte y sociedad: léxico de praxiología motriz. Barcelona: Paidotribo, 2001.

PARLEBAS, P. Perspectivas para una educación física moderna. Málaga: Unisporte, 1987. RIBAS, J. F. M. (Org.). Praxiologia motriz e voleibol: elementos para o trabalho pedagógico. ljuí: UNIJUÍ, 2014.

RIBAS, J. F. M. O voleibol e os "novos" olhares sobre os jogos esportivos coletivos. In: RIBAS,

J. F. M. (Org.) Praxiologia Motriz e Voleibol: elementos para o trabalho pedagógico. ljuí: Editora UNIJUÍ, 2014. p. 21-56.

RIBAS, J. F. M; BALDICERA, M. C. R; ARAÚJO, P. A; TOGNI, E. Preparando Para o Ataque:

Recepção. In: Ribas, J. F. M. (Org.) Praxiologia Motriz e Voleibol - Elementos para o Trabalho Pedagógico. (p. 69-80). Ijuí, Editora UNIJUÍ, 2014.

RIBAS, J.F. M; ARAÚJO, P. A. Início do Jogo: Saque. In: RIBAS, J. F. M. (Org.) Praxiologia Motriz e Voleibol - Elementos para o Trabalho Pedagógico (p. 57-67) ljuí, Editora UNIJUÍ, 2014.

SALVADOR, A. D. Métodos e técnicas de pesquisa bibliográfica. Porto Alegre: Sulina, 1986. SHONDELL, S. Recebendo Saques. In: SHONDELL, D. S; REYNAUD, C. A Bíblia do Treinador de Voleibol. Porto Alegre, Editora Artmed, 2005, p. 185-192.

TUBINO, M. J. G. Dimensões sociais do esporte. São Paulo: Cortez/ Autores Associados, 1992.

UGRINOWITSCH, C; UEHARA, P. Modalidades esportivas coletivas: o voleibol. In: ROSE JUNIOR, D. de. Modalidades Esportivas Coletivas. Rio de Janeiro, Editora Guanabara Koogan, 2011, p. $166-179$. 
WISE, M. Saque. In: SHONDELL, D. S; REYNAUD, C. A Bíblia do Treinador de Voleibol.

Porto Alegre, Editora Artmed, 2005, p. 173-183.

Recebido em: agosto/2016

Aprovado em: abril/2017 